\title{
KAJIAN KERENTANAN GEMPABUMI PADA SEKOLAH DAN PASAR DI DKI JAKARTA MENGGUNAKAN METODE KAJI CEPAT
}

\section{SEISMIC VULNERABILITY ASSESSMENT ON SCHOOLS AND PUBLIC MARKETS IN JAKARTA USING RAPID ASSESSMENT METHOD}

\author{
Mulyo Harris Pradono \\ Pusat Teknologi Reduksi Risiko Bencana \\ Badan Pengkajian dan Penerapan Teknologi \\ Gedung 820, GEOSTECH, PUSPIPTEK, Kota Tangerang Selatan \\ email: mulyo.harris@bppt.go.id
}

\begin{abstract}
Rapid assessment method to determine the earthquake vulnerability of buildings is being built in the Center for Disaster Risk Reduction Technology, BPPT. This method produces a relationship curve between number of floors, distance between columns, and the column width. These curves are built on the assumption of concrete compressive strength of $30 \mathrm{MPa}$, steel reinforcement tensile strength of $390 \mathrm{MPa}$, and concrete reinforcement ratio of 0:02. Assessment on site is done by testing the strength of concrete columns, scanning the number and dimensions of the steel reinforcement, measuring the dimensions of the column, distance between columns, record the number of floors, year of construction, function of the building, and the shape of the building. All data is compared to the assumptions when making the curves. The comparison is expressed in percentage values in order to calculate the building resilience percentage against the earthquake hazard in Jakarta. Vulnerability of the buildings is value 1 minus the percentage value of the building resilience.
\end{abstract}

Keywords: Rapid Assessment, Earthquakes, Highrise Buildings, Vulnerability

\begin{abstract}
ABSTRAK
Metode kaji cepat untuk menentukan kerentanan gempabumi suatu gedung sedang dibangun di Pusat Teknologi Reduksi Risiko Bencana, BPPT. Metode ini menghasilkan sebuah kurva hubungan antara jumlah lantai, jarak antarkolom, dan lebar kolom. Kurva ini dibangun berdasarkan asumsi kuat tekan beton $30 \mathrm{MPa}$, kuat tarik baja tulangan $390 \mathrm{MPa}$, dan rasio tulangan beton sebesar 0,02 . Pengkajian di lapangan dilakukan dengan menguji kuat tekan beton kolom, memindai jumlah dan dimensi tulangan baja, mengukur dimensi kolom, jarak antar kolom, mencatat jumlah lantai, tahun pembangunan, fungsi gedung, dan bentuk gedung. Semua data direlatifkan terhadap data asumsi pembuatan kurva. Relativitas ini dinyatakan dalam nilai persentase untuk menghitung persentase ketahanan gedung terhadap ancaman gempabumi di DKI Jakarta. Kerentanan gedung adalah nilai 1 dikurangi persentase ketahanan gedung.
\end{abstract}

Katakunci: Kaji Cepat, Gempabumi, Gedung Bertingkat, Kerentanan 


\section{PENDAHULUAN}

Kejadian gempabumi di DKI Jakarta pada tahun 2007 dan 2009 mengingatkan kembali perlunya mempersiapkan bangunan agar kuat menahan gaya gempa. Intensitas gempa pada kedua gempa tersebut diskalakan pada MMI IV-V. Kedua kejadian tersebut menimbulkan kepanikan pada penghuni gedung akibat guncangan yang cukup signifikan. Beberapa gedung bertingkat mengalami kerusakan, walaupun dikategorikan sebagai kerusakan nonstruktural. Kerusakan yang terjadi meliputi retak diagonal pada dinding, jatuhnya plafon, retaknya lantai dilatasi, dan kerusakan lain yang terlihat mata. Kerusakan ini tidak merusak struktur bangunan, yaitu kolom, balok, pelat lantai, dan dinding struktur (Pradono dan Triwinanto, 2010).

Pada tahun 2010, Kementerian Pekerjaan Umum mengeluarkan Peta Ancaman Bahaya Gempa Bumi 2010 (Kemen. PU, 2010). Studi oleh Pradono (2013), menunjukkan bahwa intensitas gempabumi DKI Jakarta berdasarkan peta tersebut adalah MMI VII untuk gempabumi 500 tahunan, dan MMI VIII untuk gempabumi 1.000 dan 2.500 tahunan. Percepatan getaran puncak di permukaan bumi untuk MMI $\vee$ adalah 0,04 $g-0,09 g\left(g=9,8\right.$ meter $/$ detik $\left.^{2}\right)$, sedangkan percepatan puncak di permukaan bumi untuk MMI VII adalah 0,18 $g-0,34 \mathrm{~g}$, dan MMI VIII adalah 0,34 $g-0,65 g$ (Wikipedia, 2013). Mengacu kepada skala intensitas gempa dan percepatan puncak di permukaan bumi di atas, maka kejadian gempa di Jakarta pada tahun 2007 dan 2009 dengan intensitas MMI V adalah kecil dibandingkan dengan intensitas ancaman gempabumi yang bisa terjadi di Jakarta menurut Peta Ancaman Bahaya Gempa Bumi.

Walaupun gedung-gedung di DKI Jakarta sudah melalui pemeriksaan desain yang sangat ketat oleh pemerintah. Tetapi setelah desain disetujui, pelaksanaan pembangunan gedung tidak menjadi tanggung jawab pemerintah lagi untuk mengawasi. Kurangnya pengawasan berpotensi terhadap terjadinya perbedaan-perbedaan dari desain semula. Oleh sebab itu diperlukan sebuah metode untuk mengkaji kerentanan gedung-gedung bertingkat di DKI Jakarta dengan tingkat ancaman gempabumi sesuai dengan yang dikeluarkan oleh Kementerian Pekerjaan Umum.

Pradono (2015) telah membangun kurva hubungan antara jumlah lantai, jarak antar kolom, dan lebar kolom untuk menilai kerentanan sebuah bangunan secara cepat, untuk kegempaan daerah DKI Jakarta. Data yang diperlukan diperoleh secara cepat di lapangan dengan melakukan pengukuran kuat tekan beton dan dimensi tulangan baja di dalam kolom. Data lain juga diperlukan, misalnya untuk bentuk yang tidak beraturan diberikan faktor reduksi tertentu.

Dalam makalah ini, dipaparkan aplikasi metode kaji cepat kerentanan gempabumi gedung bertingkat pada sekolah dan pasar.

\section{METODE PENELITIAN}

\subsection{Waktu dan Tempat Penelitian}

Penelitian dalam kaji cepat kerentanan gedung sekolah dan pasar dilakukan pada jangka waktu mulai tanggal 11 November 2015 sampai dengan 16 November 2015 berlokasi di DKI Jakarta. Sekolah yang dilakukan pengkajian adalah tiga gedung sekolah dasar negeri di Jakarta. Pasar yang dilakukan pengkajian adalah pasar milik pemerintah daerah DKI Jakarta, berjumlah dua buah gedung pasar.

\subsection{Bahan dan Data}

Kurva hubungan antara jumlah lantai, jarak antar kolom, dan lebar kolom dibuat berdasarkan asumsi kuat tekan beton $30 \mathrm{MPa}$, kuat tarik baja tulangan $390 \mathrm{MPa}$, dan rasio tulangan beton sebesar 0,02 (Pradono, 2015). Kurva ditunjukkan pada Gambar 1 berikut.

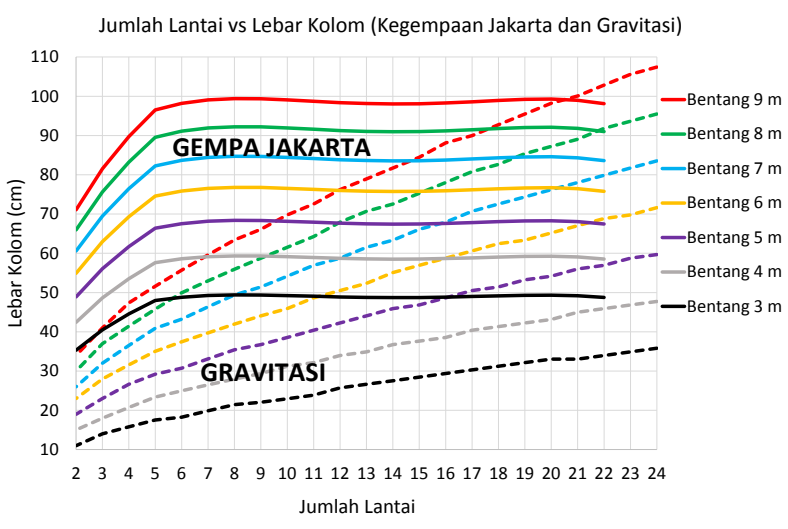

Gambar 1. Kurva Hubungan Antara Jumlah Lantai, Jarak Antar Kolom, dan Lebar Kolom untuk Daerah Kegempaan DKI Jakarta (Pradono, 2015)

Untuk memperoleh data dilakukan beberapa pengujian dan pengumpulan data sebagai berikut:

1. Pengujian kuat tekan beton kolom dengan Hammer Test.

2. Pemindaian jumlah dan dimensi tulangan baja dengan Profometer. 
3. Pengukuran dimensi kolom dan jarak antar kolom dengan meteran dan lasermeter.

4. Pendataan jumlah lantai, tahun pembangunan, fungsi gedung, dan bentuk gedung.

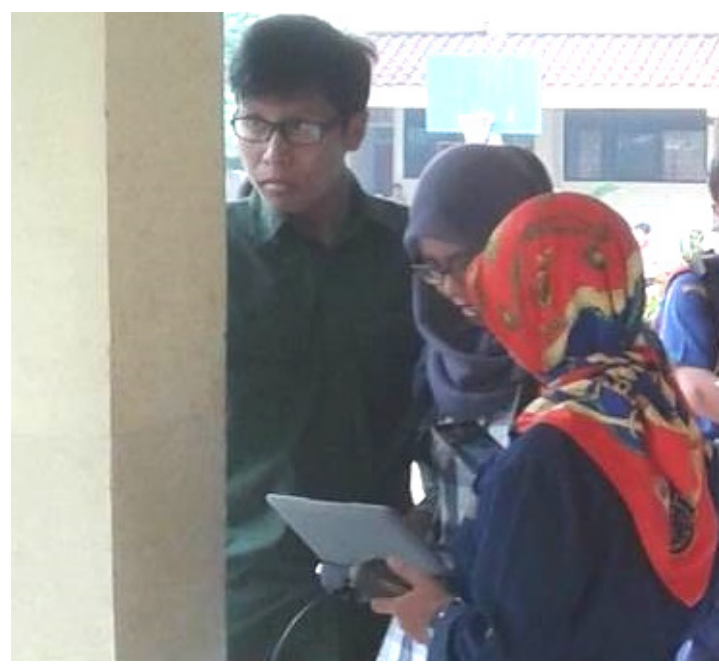

Gambar 2. Pengukuran Dimensi Kolom Beton Gedung Sekolah Menggunakan Meteran

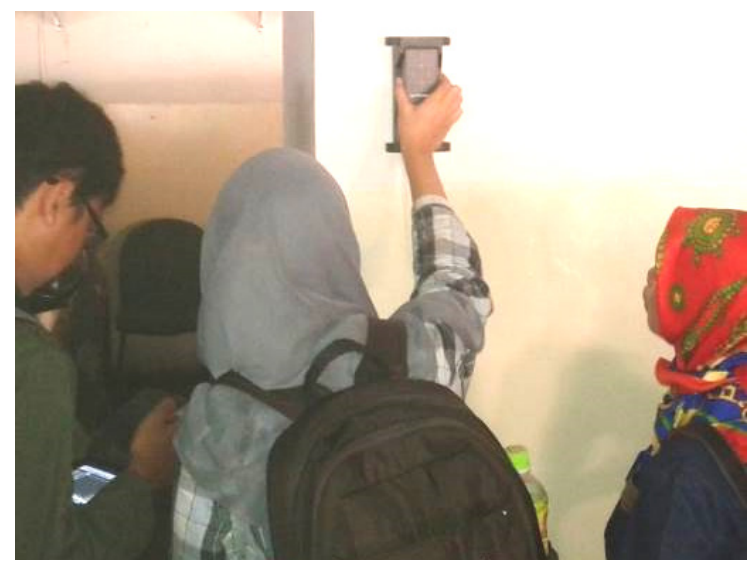

Gambar 3. Pengujian Dimensi Tulangan Baja pada Kolom Beton Gedung Pasar Menggunakan Profometer
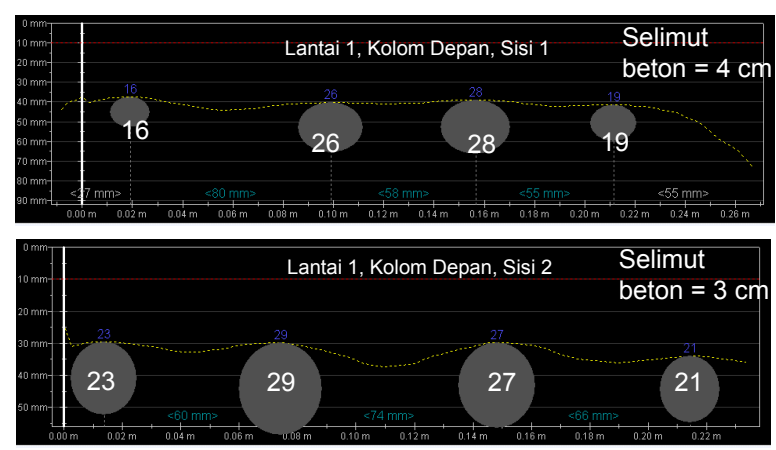

Gambar 4. Hasil Pengujian Dimensi Tulangan Baja pada Kolom Beton Menunjukkan Dimensi dan Sebaran Tulangan

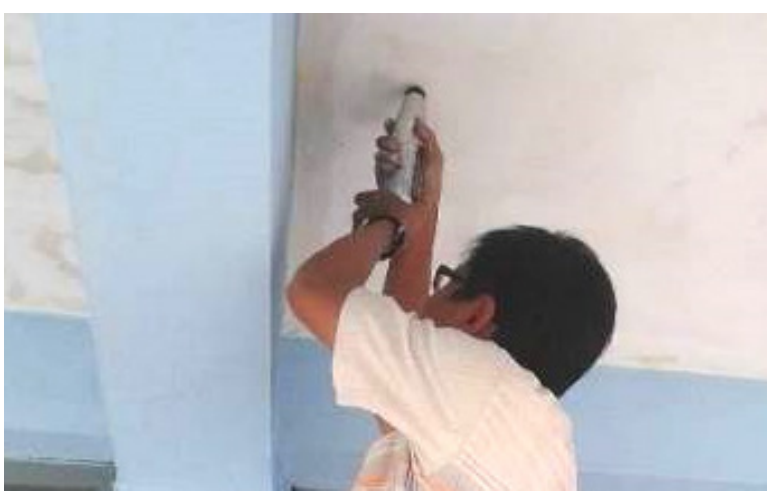

Gambar 5. Pengujian Kuat Tekan Pelat Lantai Beton Menggunakan Hammer Test

Tabel 1. Hasil Pengujian dengan Hammer menunjukkan Nilai Pantul yang Dikonversi ke Kuat Tekan Kubus Beton

\begin{tabular}{|c|c|c|}
\hline No & Nilai Pantul (datar) & Nilai Kubus Beton (MPa) \\
\hline 1 & 44 & 42 \\
\hline 2 & 42 & 38 \\
\hline 3 & 44 & 42 \\
\hline 4 & 42 & 38 \\
\hline 5 & 44 & 42 \\
\hline 6 & 43 & 40 \\
\hline 7 & 39 & 33 \\
\hline 8 & 44 & 42 \\
\hline 9 & 44 & 42 \\
\hline 10 & 44 & 42 \\
\hline 11 & 41 & 36 \\
\hline 12 & 43 & 40 \\
\hline 13 & 40 & 34 \\
\hline 14 & 40 & 34 \\
\hline 15 & 38 & 31 \\
\hline 16 & 38 & 31 \\
\hline 17 & 44 & 42 \\
\hline 18 & 46 & 46 \\
\hline 19 & 46 & 46 \\
\hline 20 & 44 & 42 \\
\hline & & \\
\hline
\end{tabular}

\subsection{Analisis Data}

Data pada Tabel 1 direlatifkan terhadap data asumsi pembuatan kurva, dengan cara sebagai berikut:

a. Relativitas data diperoleh terhadap asumsi pembuatan kurva dinyatakan dalam nilai persentase.

b. Persentase ini digabung untuk menghitung persentase ketahanan gedung terhadap ancaman gempabumi di DKI Jakarta.

c. Kerentanan gedung adalah nilai 1 dikurangi persentase ketahanan gedung. 


\section{HASIL DAN PEMBAHASAN}

\subsection{Hasil}

Setelah dilakukan pengujian dan pengumpulan data pada tiga sekolah dasar dan dua pasar pemerintah, maka semua hasil dirangkum dalam Tabel 2 berikut.

Tabel 2. Data Hasil Pengujian

\begin{tabular}{|c|c|c|c|c|c|}
\hline No & $\begin{array}{c}\text { Fungsi } \\
\text { Gedung }\end{array}$ & $\begin{array}{c}\text { Tahun } \\
\text { Ba- } \\
\text { ngun }\end{array}$ & $\begin{array}{c}\text { Jml } \\
\text { Lantai }\end{array}$ & $\begin{array}{c}\text { Jarak } \\
\text { Kolom } \\
{[\mathrm{m}]}\end{array}$ & $\begin{array}{c}\text { Ben- } \\
\text { tuk } \\
\text { Ge- } \\
\text { dung }\end{array}$ \\
\hline 1 & $\begin{array}{c}\text { Sekolah } \\
\text { Dasar }\end{array}$ & 2012 & 3 & 4 & $\begin{array}{c}\text { Ber- } \\
\text { aturan }\end{array}$ \\
\hline 2 & Pasar & 2012 & 10 & 8 & $\begin{array}{c}\text { Ber- } \\
\text { aturan }\end{array}$ \\
\hline 3 & $\begin{array}{c}\text { Sekolah } \\
\text { Dasar }\end{array}$ & 1989 & 2 & 4 & $\begin{array}{c}\text { Ber- } \\
\text { aturan }\end{array}$ \\
\hline 4 & Pasar & 1999 & 7 & 8 & $\begin{array}{c}\text { Ber- } \\
\text { aturan }\end{array}$ \\
\hline 5 & $\begin{array}{c}\text { Sekolah } \\
\text { Dasar }\end{array}$ & 1972 & 3 & 4 & $\begin{array}{c}\text { Ber- } \\
\text { aturan }\end{array}$ \\
\cline { 5 - 6 }
\end{tabular}

Tabel 2. Data Hasil Pengujian (Lanjutan)

\begin{tabular}{|c|c|c|c|c|c|}
\hline \multirow{2}{*}{ No } & \multicolumn{2}{|c|}{$\begin{array}{l}\text { Lebar Kolom } \\
\qquad[\mathrm{cm}]\end{array}$} & \multirow{2}{*}{$\begin{array}{c}\text { Kuat } \\
\text { Tekan } \\
\text { Beton } \\
\text { [MPa] }\end{array}$} & \multirow{2}{*}{$\begin{array}{c}\text { Rasio } \\
\text { Baja } \\
\text { thd } \\
\text { Beton }\end{array}$} & \multirow{2}{*}{$\begin{array}{c}\text { Selimut } \\
\text { beton } \\
\text { [mm] }\end{array}$} \\
\hline & $\begin{array}{l}\text { Ter- } \\
\text { ukur }\end{array}$ & Grafik & & & \\
\hline \multirow{2}{*}{1} & \multirow{2}{*}{30} & \multirow{2}{*}{48} & \multirow{2}{*}{44} & \multirow{2}{*}{0,08} & 40 \\
\hline & & & & & 30 \\
\hline 2 & 80 & 92 & 39 & 0,04 & 50 \\
\hline \multirow{2}{*}{3} & 28 & 43 & \multirow{2}{*}{21} & \multirow{2}{*}{0,03} & 30 \\
\hline & 44 & 61 & & & 60 \\
\hline 4 & 71 & 92 & 42 & 0,04 & 45 \\
\hline \multirow{2}{*}{5} & 28 & 48 & \multirow{2}{*}{45} & \multirow{2}{*}{0,02} & 30 \\
\hline & 57 & 70 & & & 50 \\
\hline
\end{tabular}

Data lebar kolom direlatifkan terhadap lebar kolom yang diperoleh dari grafik, seperti ditunjukkan pada Tabel 3. Dengan menggunakan kurva hubungan antara kapasitas kolom dan lebar kolom (Gambar 5), yang sudah dibahas dalam Pradono et al. (2015a), maka dapat dibandingkan antara kapasitas kolom terukur (data) dan kapasitas kolom seharusnya (grafik). Perbedaan ini kemudian dirasiokan. Hasilnya disajikan pada kolom terakhir Tabel 3
Tabel 3. Rasio antara Kapasitas Kolom Terukur dan Kapasitas Seharusnya (Pradono et al., 2015b)

\begin{tabular}{|c|c|c|c|c|c|}
\hline \multirow{2}{*}{ No } & \multicolumn{2}{|c|}{$\begin{array}{c}\text { Lebar/ Diameter } \\
\text { Kolom [cm] }\end{array}$} & \multicolumn{2}{|c|}{$\begin{array}{c}\text { Kapasitas Kolom } \\
{[\text { MN.m] }}\end{array}$} & \multirow{2}{*}{$\begin{array}{c}\text { Rasio } \\
{[\%]}\end{array}$} \\
\cline { 2 - 5 } & Data & Grafik & Data & Grafik & \\
\hline 1 & 30 & 48 & 0,09 & 0,38 & 23 \\
\hline 2 & 80 & 92 & 1,90 & 2,95 & 64 \\
\hline \multirow{2}{*}{3} & 28 & 43 & 0,07 & 0,27 & 26 \\
\cline { 2 - 5 } & 44 & 61 & 0,29 & 0,81 & 36 \\
\hline 4 & 71 & 92 & 0,93 & 2,95 & 31 \\
\hline \multirow{2}{*}{5} & 28 & 48 & 0,07 & 0,38 & 18 \\
\cline { 2 - 5 } & 57 & 70 & 0,66 & 1,25 & 52 \\
\hline
\end{tabular}

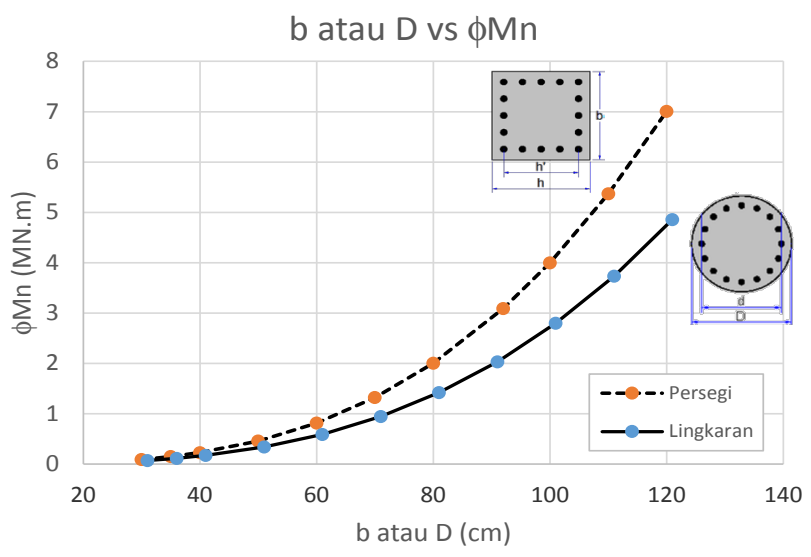

Gambar 5. Grafik Hubungan antara Dimensi Kolom dengan Kapasitas Momen Kolom (Pradono et al., 2015a)

Dari nilai pada Tabel 3 di atas, dapat disimpulkan bahwa umumnya kapasitas kolom terukur lebih rendah daripada kapasitas seharusnya. Akan tetapi belum dimasukkan data tebal selimut beton yang dapat mempengaruhi kapasitas kolom. Jadi, data berikutnya berupa selimut beton digunakan untuk menganalisis kapasitas kolom. Pengaruh dari tebal selimut beton terhadap kapasitas kolom ditunjukkan pada Gambar 6 di bawah.

\section{h'/h vs $\phi M n /\left(f c^{\prime} . A g . h\right)$}

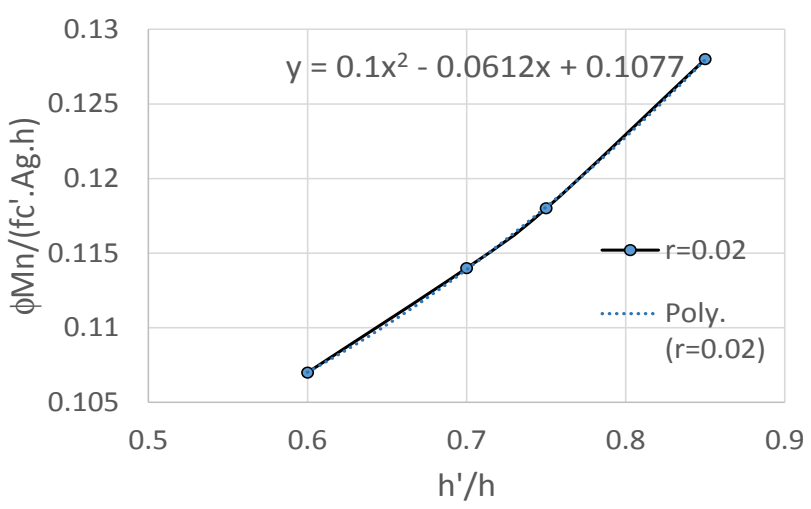

Gambar 6. Grafik Pengaruh Tebal Selimut Beton terhadap Kapasitas Kolom (Pradono et al., 2015a) 
Nilai-nilai selimut beton yang didapat dari lapangan menggunakan Profometer dirangkum pada Tabel 4 di bawah. Nilai tebal selimut digunakan untuk mencari jarak kopel tulangan h'. Lebar kolom disimbolkan sebagai h. Rasio h'/h dimasukkan dalam kurva dan didapat nilai kapasitas kolom. Nilai ini direlatifkan terhadap nilai kapasitas kolom benchmark menggunakan h'/h sebesar 0,134.

Tabel 4. Pengaruh Tebal Selimut Beton terhadap Kapasitas Kolom

\begin{tabular}{|c|c|c|c|c|c|c|}
\hline No & $\begin{array}{c}\text { Data } \\
\text { Lebar } \\
\text { Kolom } \\
\text { h } \\
{[\mathrm{cm}]}\end{array}$ & $\begin{array}{c}\text { Se- } \\
\text { limut } \\
\text { Beton } \\
\text { [mm] }\end{array}$ & $\begin{array}{c}h^{\prime} \\
{[\mathrm{cm}]}\end{array}$ & $h^{\prime} / h$ & $\begin{array}{c}\text { Mn/ } \\
\text { (fc'. } \\
\text { Ag.h) }\end{array}$ & $\begin{array}{c}\text { Rasio } \\
\text { thd } \\
\text { bench } \\
\text { mark } \\
{[\%]}\end{array}$ \\
\hline \multirow{2}{*}{1} & \multirow{2}{*}{30} & 40 & 19,8 & 0,66 & 0,111 & 83 \\
\hline & & 30 & 21,5 & 0,72 & 0,115 & 86 \\
\hline \multirow{2}{*}{2} & \multirow{2}{*}{80} & \multirow{2}{*}{50} & 67,0 & 0,84 & 0,127 & 95 \\
\hline & & & 67,2 & 0,84 & 0,127 & 95 \\
\hline \multirow{2}{*}{3} & 28 & 30 & 20,3 & 0,73 & 0,116 & 87 \\
\hline & 44 & 60 & 30,8 & 0,70 & 0,114 & 85 \\
\hline 4 & 71 & 45 & 58,8 & 0,83 & 0,126 & 94 \\
\hline \multirow{2}{*}{5} & 28 & 30 & 19,9 & 0,71 & 0,115 & 86 \\
\hline & 57 & 50 & 45,4 & 0,80 & 0,122 & 92 \\
\hline \multicolumn{2}{|c|}{ Benchmark } & 40 & & 0,90 & 0,134 & 100 \\
\hline
\end{tabular}

Setelah masing-masing rasio dari data diperoleh, maka selanjutnya dimasukkan dalam Tabel 5 berikut. Nilai masing-masing persentase data dikalikan untuk mendapatkan hasil akhir berupa nilai ketahanan gedung terhadap gempa DKI Jakarta (Tabel 5).

Tabel 5. Analisis Relativitas Tiap Data

\begin{tabular}{|c|c|c|c|c|}
\hline No & $\begin{array}{c}\text { Tahun } \\
\text { Bangun* } \\
{[\%]}\end{array}$ & $\begin{array}{c}\text { Lebar } \\
\text { Kolom } \\
{[\%]}\end{array}$ & $\begin{array}{c}\text { Kuat } \\
\text { Beton } \\
{[\%]}\end{array}$ & $\begin{array}{c}\text { Rasio } \\
\text { Baja } \\
{[\%]}\end{array}$ \\
\hline 1 & 100 & 23 & 146 & 400 \\
\hline 2 & 100 & 64 & 130 & 200 \\
\hline \multirow{2}{*}{3} & 100 & 26 & \multirow{2}{*}{70} & 150 \\
\cline { 2 - 3 } 4 & 100 & 36 & 140 & 200 \\
\hline \multirow{2}{*}{5} & \multirow{2}{*}{33} & 18 & \multirow{2}{*}{150} & \multirow{2}{*}{100} \\
\cline { 3 - 3 } & & 52 & & \\
\hline
\end{tabular}

Tabel 5. Analisis Relativitas Tiap Data (lanjutan)

\begin{tabular}{|c|c|c|c|c|}
\hline No & $\begin{array}{c}\text { Selimut } \\
\text { Beton } \\
{[\%]}\end{array}$ & $\begin{array}{c}\text { Bentuk } \\
\text { Gedung } \\
{[\%]^{\star *}}\end{array}$ & $\begin{array}{c}\text { Ketahan- } \\
\text { an thd } \\
\text { Gempa } \\
\text { R } \\
{[\%]}\end{array}$ & $\begin{array}{c}\text { Kerentan- } \\
\text { an thd } \\
\text { Gempa } \\
\text { V } \\
{[\%]^{\star * *}}\end{array}$ \\
\hline \multirow{2}{*}{1} & 83 & \multirow{2}{*}{100} & 111 & 0 \\
\hline & 86 & & 115 & 0 \\
\hline \multirow{2}{*}{2} & 95 & \multirow{2}{*}{100} & 158 & 0 \\
\hline & 95 & & 158 & 0 \\
\hline \multirow{2}{*}{3} & 87 & \multirow{2}{*}{100} & 24 & 76 \\
\hline & 85 & & 32 & 68 \\
\hline 4 & 94 & 100 & 82 & 18 \\
\hline \multirow{2}{*}{5} & 86 & \multirow{2}{*}{100} & 8 & 92 \\
\hline & 92 & & 24 & 76 \\
\hline
\end{tabular}

*Untuk gedung dibangun sebelum tahun 1981, maka dikalikan 0,33 karena masih didesain menggunakan prinsip elastis.

${ }^{* *}$ Bentuk gedung beraturan: nilai $100 \%$, tidak beraturan: nilai $75 \%$.

***Kerentanan terhadap gempa adalah nilai $100 \%$ dikurangi persentase ketahanan terhadap gempa.

\subsection{Pembahasan}

Metode ini sebenarnya menghasilkan data berupa ketahanan gedung terhadap gempabumi di DKI Jakarta. Akan tetapi yang ingin dicari adalah kerentanan gedung, maka kerentanan gedung dihitung berdasarkan formula di bawah, di mana $V$ adalah kerentanan gedung (dalam \%) dan $C$ adalah ketahanan gedung (dalam \%).

$$
V=100 \%-C
$$

Nilai kerentanan ini digunakan untuk menentukan tingkat risiko bangunan terhadap gempabumi. Dalam hal ini adalah khusus untuk daerah DKI Jakarta. Untuk daerah lain perlu dibuat kurva hubungan antara dimensi kolom dengan jumlah lantai berdasarkan data kegempaan dari Kementerian PU (Kemen PU, 2010).

\section{KESIMPULAN}

Berdasarkan hasil kajian di atas, maka dapat disimpulkan beberapa hal sebagai berikut:

1. Metode di atas untuk melakukan kajian cepat kerentanan gedung adalah cukup sederhana dan bisa dilakukan dalam waktu setengah hari untuk satu gedung karena hanya memerlukan data:

a. Kuat beton.

b. Rasio tulangan terhadap beton. 
c. Dimensi kolom dan jarak antar kolom.

d. Jumlah lantai, fungsi, tahun desain, dan bentuk dari gedung.

2. Dengan semakin banyaknya gedung yang dikaji, dapat digunakan untuk menggambarkan sebaran kerentanan gedung-gedung di Jakarta dan kota-kota lain di Indonesia.

3. Metode ini dapat dijadikan dasar untuk studi lebih lanjut mengenai retrofitting (perkuatan) jika dianggap bangunan belum memenuhi standar minimal kekuatan.

\section{DAFTAR PUSTAKA}

Kemen PU. 2010. Peta Hazard Gempa Indonesia 2010, Kementerian Pekerjaan Umum, Juli.

Pradono, M. H. dan P. Triwinanto. 2010. Evaluasi Kekuatan Struktur Gedung BPPT Pasca Gempa Tasikmalaya 2 September 2009. Dalam: Jurnal Sains dan Teknologi Mitigasi Bencana. Vol. 5. No. 1. Hal.: 16-30.

Pradono, M. H. 2013. Intensitas Gempabumi DKI Jakarta berdasarkan Peta Hazard Gempa Indonesia 2010. Dalam: Jurnal Sains dan Teknologi Mitigasi Bencana. Vol. 8. No. 1. Juni. Hal.: 1-8.

Pradono, M. H. 2015. Kaji Cepat Kerentanan Sismik Gedung Bertingkat menggunakan Data Dimensi dan Material Gedung. Dalam: Jurnal Riset Kebencanaan Indonesia. Vol. 1. No. 2. Oktober. Hal.: 65-71.

Pradono, M. H., Y. Adityawarman, dan Udrekh. 2015a. Technical Document WBS 4 Pilot Plan Teknologi EQ Ready Building, Tahap III Critical Program Review, No. TD 3 / MHP / WBS-4 / PPTRRB / 2015, Pengkajian dan Penerapan Teknologi Reduksi Risiko Bencana 2015. Badan Pengkajian dan Penerapan Teknologi, September.

Pradono, M. H., Y. Adityawarman, dan Udrekh. 2015b. Technical Document WBS 4 Pilot Plan Teknologi EQ Ready Building, Tahap IV Final Program Review, No. TD 4 / MHP / WBS-4 / PPTRRB / 2015, Pengkajian dan Penerapan Teknologi Reduksi Risiko Bencana 2015. Badan Pengkajian dan Penerapan Teknologi, September.

\section{UCAPAN TERIMA KASIH}

Ucapan terima kasih disampaikan kepada BPBD DKI Jakarta dan rekan-rekan di PTRRB BPPT yang telah membantu terlaksanananya kegiatan ini. Ucapan terima kasih juga disampaikan kepada Kepala Sekolah SDN 09 Benhil, SDN 01-02 Kembangan Selatan, SDN 011-012 Rawa Bunga, dan Pengelola Pasar Cikini CGC serta Pasar Glodok PD Pasar Jaya. 